\title{
Biosimilar Versus Generic Drugs: Same But Different?
}

\author{
Katelijne van de Vooren • Alessandro Curto • \\ Livio Garattini
}

Published online: 5 February 2015

(c) Springer International Publishing Switzerland 2015

\section{Introduction}

Research and development characterizes the pharmaceutical industry, and the flow of new drugs is protected by patents to remunerate this investment. Once a patent expires, price competition is possible, since any manufacturer can copy the originator product. This circumstance justifies the place in the pharmaceutical market for generics and biosimilars, i.e. off-patent medicines to be sold at lower prices than their originators.

While generics have been widely used throughout the world for decades, this is not yet the case for the more recent biosimilars, of which only six have been approved by the European Medicines Agency (EMA) so far [1] Here, we compare these two types of off-patent medicines to highlight their differences, particularly what makes biosimilars peculiar beyond the way they are produced. We mainly refer to Western European countries, since generics have been in use there for decades alongside in-patent drugs.

\section{Comparative Analysis}

A generic medicine is a chemically derived drug developed to be equivalent to an originator that has already been authorised. Only the inactive ingredients (or 'excipients') may differ in the generic and its originator [2]. The concept of bioequivalence is fundamental for generics. These small

K. van de Vooren · A. Curto $\cdot$ L. Garattini $(\square)$

CESAV, Center for Health Economics, IRCCS Institute

for Pharmacological Research 'Mario Negri',

Via Camozzi 3, 24020 Ranica, Italy

e-mail: lgarattini@marionegri.it and not very complicated chemical entities are relatively easy to synthesize and have predictable performance in humans, since they are exact copies of the originators.

A biosimilar product is developed to be similar to an original biological medicine whose patent has expired. The active ingredient of a biosimilar and its originator are essentially the same biological substance, though there may be minor differences due to their complex nature and production methods [3]. According to the EMA [3] neither an 'inferior' nor a 'superior' product should be approved as a biosimilar, due to the potential for different biological activity and/or safety. A biosimilar needs an extensive head-to-head comparison with the originator to ensure close resemblance in physicochemical and biologic characteristics, safety, and efficacy. In practice, the type and amount of clinical data required for each biosimilar can vary widely, depending on (1) the complexity of the active substance and how well it can be characterized, (2) the availability of an accepted surrogate endpoint to compare efficacy, (3) the type and seriousness of safety concerns that the reference product encountered, (4) the possibility of extrapolating efficacy and safety data to other indications of the reference product that have not been studied for the biosimilar. In theory, if the relevant mechanism of action of the active substance and the target receptor(s) involved in the tested and extrapolated indication(s) are the same, extrapolation should not be a problem [4].

Most generics and the few biosimilars approved thus far are prescribed in quite different settings [5], which vary according to the healthcare system framework. The former are mainly prescribed in primary care by general practitioners (GPs), who are self-employed independent practitioners in most Western EU countries; the latter are used more by specialists, particularly hospital doctors, who are 
employees in all countries but The Netherlands [6]. Thus, their distribution channels can differ significantly. Generics are primarily dispensed through community pharmacies in all countries, while biosimilars are usually first used in hospitals, so the influence of community pharmacists is still limited overall.

An important issue for generics in the long run, worldwide, is patients' perceptions of the safety and quality of products marketed, mainly influenced by health professionals. Pharmaceutical companies sometimes have an obvious interest in discrediting generics and undermining their credibility among prescribers [7], who in turn are reluctant to favour their widespread prescription without any financial incentive from health authorities to compensate their loss of influence. Broadly, community pharmacists are keener about generics, their interest mainly depending on whether commercial incentives offered by the manufacturer of the generic more than compensate their lower margins (than the originators) and the extra time needed to inform patients.

Biosimilars still encounter substantial barriers when competing with branded originators for market share. Third-party payers seem cautious about supporting their diffusion, probably because they are still unsure how to interpret the concept of similarity, and fear immunogenicity. Another big hurdle seems to be extrapolation to other indications for the biosimilar when the originator has multiple indications (e.g. epoetin and infliximab) and similarity has been demonstrated by clinical trials (CTs) only for one at approval. The 'similar but not identical' principle and the traditional use of CTs to judge efficacy and safety may lead to suspicion in the different medical consultants involved in their prescription, even though extrapolation is based on rigorous characterisation and comparison of structural and functional characteristics using state-of-the-art analytical tools [4]. Furthermore, extrapolation of data has been accepted for many years, even when major changes are made to the manufacturing process of originators [4]. In general, the employee status of medical consultants and hospital pharmacists in the Western EU countries should facilitate the introduction by health authorities of budgetary tools to enhance the promotion of biosimilars.

Approval for marketing a generic usually requires only limited investments in clinical safety and efficacy. This can lead to prices $50 \%$ lower than originators, even $80 \%$ in many cases [8]. Most national authorities have set specific pricing and reimbursement schemes for generics to encourage their widespread diffusion and thus contain pharmaceutical expenditure [9]. The most widely adopted price regulation in the Western EU countries has been the so called 'reference pricing' scheme, whereby health authorities set a maximum price for products that have the same active ingredient so the cost of equivalent products exceeding the reference has to be covered by the patient [10].

As an average, prices of biosimilars are only discounted 20-35\% compared with the originators so far [11]. Companies justify this relatively small price difference with the considerable investment needed to develop and market a biosimilar [12]. Current biosimilar pricing in Western EU countries is still unclear and uneven. Countries like Germany and The Netherlands have included the first biosimilars approved (epoetin and filgrastim) under reference pricing like generics, but in countries like Italy [13] and Spain [14] many regional authorities purchase biosimilars through tenders.

\section{Policy Implications}

Biosimilars are the 'new' off-patent medicines made via a biological process. A few biosimilars are on the European markets at present, but interest is being spurred by a number of top-selling biologics about to become off-patent in the next 5 years [15].

The characteristics of biosimilars differ from those of generics, which have simple small chemical structures and are considered to be identical to their reference medicines. The complexity of the biological/biotechnology-derived products renders the standard generic procedure based on bioequivalence not applicable, and a specific approach based on a comprehensive comparability exercise including CTs must be followed [16]. The complicated biological production process, even though it greatly influences the characteristics of the end product, is kept a company secret. Disclosure of the production process could lead to easier and more exact copying of the originator [4].

In principle, since hospitals and health authorities employ specialists, it should be easier for them to promote biosimilars. In contrast with what happens with the attitudes of GPs and community pharmacists towards generics, health authorities could exploit straightforward managerial tools to enhance biosimilar prescription through budgeting.

The oft-mentioned concern about the quality of generics should not play a major role for biosimilars. Not only are there only a few manufacturers-who are easy to controlbut most of them are well established companies in the pharmaceutical field. Moreover, annual periodic safety update reports from the EMA for these drugs have not yet identified differences between biosimilars and reference products in frequency, type, or severity of adverse events [11]. To our knowledge, the only accident thus far relating to biologics involved batches of the epoetin originator [17].

Like generics, biosimilars are unlikely to earn a place in the pharmaceutical arsenal without inducing considerable 
savings for health authorities. The manufacturers' claim that price cuts on biosimilars should be much smaller than on generics seems questionable. The higher development costs for biosimilars compared with generics are partly justified by the CTs required for approval and partly by the more complicated production process. While CT costs could be reduced simply by different patent regulation, fixed costs like production are hardly a major proportion of the ex-factory prices for in-patent drugs [18]. This seems even more unlikely for the monoclonal antibodies with extremely high prices whose patents shortly expire. Tenders could be the most effective tool to cut the prices of biosimilars. However, to generate substantial savings, the bid needs to be designed so that competition can produce its effects, at least allowing more than one manufacturer to compete for the same lot [19].

To conclude, the main hurdle for diffusion of biosimilars at present seems to be international patent regulation. Opening up production secrecy in ample advance of patent expiry would help biosimilars contribute more to sustainable pharmaceutical expenditure, which is particularly important in this period of unprecedented economic crisis. Here, we suggest a very general proposal for debate.

Acknowledgments Livio Garattini acts as guarantor.

Conflict of interest None.

Funding for the paper None.

\section{References}

1. European Medicines Agency. European Public Assessment Reports. Biosimilars. Available from: http://www.ema.europa.eu/ ema/index.jsp?curl=pages $\% 2$ Fmedicines $\% 2$ Flanding $\% 2$ Fepar_sea rch.jsp\&mid=WC0b01ac058001d124\&searchTab=searchByAuthT ype \&alreadyLoaded=true \&isNewQuery $=$ true $\&$ status $=$ Authorised \&status $=$ Withdrawn $\&$ status $=$ Suspended $\&$ status $=$ Refused $\&$ keywo $\mathrm{rd}=$ Enter+keywords $\&$ searchType=name $\&$ taxonomyPath $=\&$ tree Number $=\&$ searchGeneric Type $=$ biosimilars $\&$ genericsKeywordS earch=Submit. Last accessed 15 Jan 2015.

2. European Medicines Agency. Questions and answers on generic medicines. 22 November 2012. EMA/393905/2006 Rev 2. Available from: http://www.ema.europa.eu/docs/en_GB/documen t_library/Medicine_QA/2009/11/WC500012382.pdf. Last accessed 9 Dec 2014.

3. European Medicines Agency. Questions and answers on biosimilar medicines (similar biological medicinal products). 27 September 2012. EMA/837805/2011. Available from: http://
www.ema.europa.eu/docs/en_GB/document_library/Medicine_Q A/2009/12/WC500020062.pdf. Last accessed 9 Dec 2014.

4. Weise M, Kurki P, Wolff-Holz E, Bielsky MC, Schneider CK. Biosimilars: the science of extrapolation. Blood. 2014;124(22):3191-6.

5. Bocquet F, Paubel P, Fusier I, Cordonnier AL, Le Pen C, Sinègre M. Biosimilar granulocyte colony-stimulating factor uptakes in the EU-5 Markets: a descriptive analysis. Appl Health Econ Health Policy. 2014;12:315-26.

6. Schäfer W, Kroneman M, Boerma W, van den Berg M, Westert G, Devillé W, et al. The Netherlands: health system review. Health Syst Transit. 2010;12(1):5-27, 1-228.

7. Hassali MA, Wong ZY, Alrasheedy AA, Saleem F, Mohamad Yahaya AH, Aljadhey H. Perspectives of physicians practicing in low and middle income countries towards generic medicines: a narrative review. Health Policy. 2014;117(3):297-310.

8. Godman B, Shrank W, Wettermark B, Andersen M, Bishop I, Burkhardt $\mathrm{T}$, et al. Use of generics: a critical cost containment measure for all healthcare professionals in Europe? Pharmaceuticals. 2010;3(8):2470-94.

9. Garattini L, Tediosi F. A comparative analysis of generics markets in five European countries. Health Policy. 2000;51(3): 149-62.

10. Giuliani G, Selke G, Garattini L. The German experience in reference pricing. Health Policy. 1998;44(1):73-85.

11. Bennett CL, Chen B, Hermanson T, Wyatt MD, Schulz RM, Georgantopoulos $\mathrm{P}$, et al. Regulatory and clinical considerations for biosimilar oncology drugs. Lancet Oncol. 2014;15(13): e594-605.

12. Blackstone EA, Joseph PF. The economics of biosimilars. Am Health Drug Benefits. 2013;6(8):469-78.

13. Curto A, van de Vooren K, LoMuto R, Duranti S, Garattini L. Regional tenders on biosimilars in Italy, potentially competitive? GaBI J. 2013;2(3):123-9.

14. Ortega E. Medicamentos biológicos de marca y biosimilares competirán en los mismos concursos públicos. Redacción Médica 25th November 2014. http://www.redaccionmedica.com/seccione s/industria/biologicos-de-marca-y-biosimilares-competiran-en-los -mismos-concursos-publicos-5934. Last accessed 9 Dec 2014.

15. US\$67 billion worth of biosimilar patents expiring before 2020 . 20 January 2014. GaBI Journal. Available from: http://www. gabionline.net/Biosimilars/General/US-67-billion-worth-of-biosim ilar-patents-expiring-before-2020. Last accessed 9 Dec 2014.

16. European Medicines Agency, Committee for Medicinal Products for Human Use (CHMP). Guideline on similar biological medicinal products. 30 October 2005. http://www.ema.europa.eu/ docs/en_GB/document_library/Scientific_guideline/2009/09/WC5 00003517.pdf. Last accessed 9 Dec 2014.

17. Brinks V, Hawe A, Basmeleh AH, Joachin-Rodriguez L, Haselberg R, Somsen GW, et al. Quality of original and biosimilar epoetin products. Pharm Res. 2011;28(2):386-93.

18. DiMasi JA, Hansen RW, Grabowski HG. The price of innovation: new estimates of drug development costs. J Health Econ. 2003;22(2):151-85.

19. Curto S, Ghislandi S, van de Vooren K, Duranti S, Garattini L. Regional tenders on biosimilars in Italy: an empirical analysis of awarded prices. Health Policy. 2014;116(2-3):182-7. 